\title{
An analysis of issues relating to the taxation of cryptocurrencies as financial instruments
}

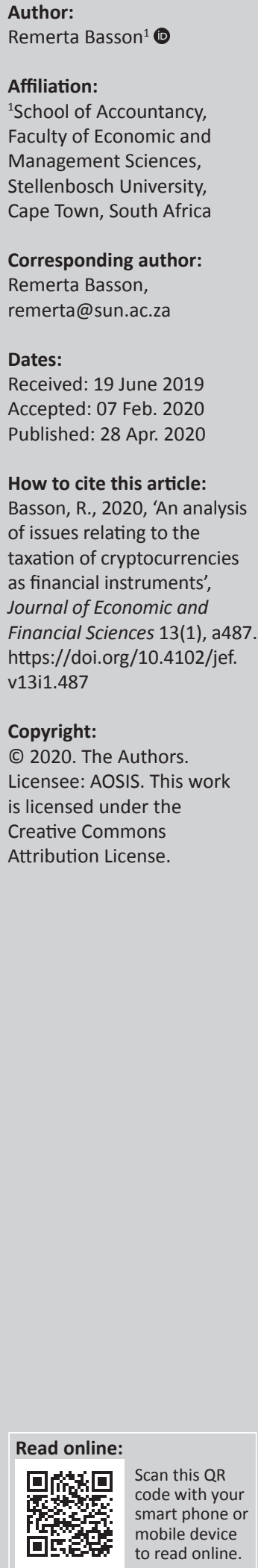

Orientation: This article examines the normal tax treatment of cryptocurrency transactions performed by natural persons in South Africa.

Research purpose: The aim of this article was to document the normal tax treatment of cryptocurrency transactions subsequent to the inclusion of cryptocurrency in the definition of 'financial instrument' in section 1(1) of the Income Tax Act No. 58 of 1962, and to determine whether this inclusion gives rise to unanticipated issues.

Motivation for the study: This investigation was necessitated by the distinguishing features of cryptocurrency that differentiate it from other financial instruments.

Research approach/design and method: This article falls within the reform-orientated genre of doctrinal research. A desktop literature review was conducted to determine the normal tax treatment of cryptocurrency transactions, based on an interpretation of relevant legislation and a review of secondary commentary. Key issues identified in the normal tax treatment of cryptocurrency transactions were documented, and recommendations were made for addressing the issues identified.

Main findings: A misalignment may occur between taxable incomes and economic gains of taxpayers engaged in cryptocurrency mining.

Practical/managerial implications: The South African Revenue Service (SARS) should allow for a deduction equivalent to the market value of cryptocurrency acquired through cryptocurrency mining in terms of section $22(2)(a)$.

Contribution/value-add: A risk of misalignment between taxable incomes and economic gains of taxpayers performing cryptocurrency mining has been identified and documented, which may inform legislative amendment, or the practice of the SARS.

Keywords: cryptocurrency; bitcoin; virtual currency; barter transactions; section 22(4).

\section{Introduction}

The definition of 'financial instrument' in section 1(1) of the Income Tax Act No. 58 of 1962 (the Act) (South African Government 1962) was amended by the Taxation Laws Amendment Act No. 23 of 2018 to include 'any cryptocurrency'. According to the Explanatory Memorandum on the Taxation Laws Amendment Bill, 2018, this amendment 'seeks to clarify that cryptocurrency is a financial instrument and would therefore not be a personal use asset for capital gains tax purposes' (National Treasury 2019:42).

Cryptocurrency refers to a virtual currency, which is both protected by cryptography and exchangeable for fiat currency (Financial Action Task Force 2014:4-5). Virtual currency is (Financial Action Task Force 2014):

$[A]$ digital representation of value that can be digitally traded and functions as (1) a medium of exchange; and/or (2) a unit of account; and/or (3) a store of value, but does not have legal tender status. (p. 4)

The discussion in this article is limited to cryptocurrencies that are intended to fulfil the functions included in this definition.

The Act of 1962 contains numerous specific provisions that override or supplement the normal tax treatment of financial instruments in terms of general tax principles (De Jager, Parsons \& Roeleveld 2012:167-169). However, these specific provisions mostly govern the normal tax treatment of specific types of derivative, equity and debt instruments, and consequently fail to find application to most cryptocurrencies. Therefore, the inclusion of cryptocurrency in the definition of 'financial 
instrument' gives legislative effect to the position of the South African Revenue Service (SARS) (SARS 2018a) that cryptocurrency transactions are taxed in terms of the general principles of the Act. Furthermore, this inclusion clarifies that cryptocurrency transactions do not fall within the ambit of section 24I of the Act, which governs the normal tax treatment of gains and losses on foreign exchange transactions.

Upon initial reflection, the decision by the legislature to tax cryptocurrency within the existing tax framework applicable to financial instruments could appear reasonable. The legislature's approach seemingly requires only minor legislative amendments and avoids the development of specific legislation dealing with cryptocurrency. Furthermore, the view of the Organisation for Economic Cooperation and Development (OECD) (OECD 1998:3) is that legislative amendments relating to new technologies should assist in the application of existing tax principles to those new technologies. The amendment appears to be in line with this view.

However, legislative amendments may often lead to unanticipated issues (Maroun 2015:159). In this particular case, there may be an increased risk of unanticipated issues because the nature of cryptocurrency differs significantly from that of other items included in the definition of 'financial instrument' in section 1(1) of the Act. In spite of the fact that the majority of cryptocurrency transactions may currently be speculative in nature (Baur, Hong \& Lee 2018:187), cryptocurrency was initially created as an alternative to transacting through third-party intermediaries (Nakamoto 2008:1). The intended use of cryptocurrency as a method of payment distinguishes it from other items included in the definition of 'financial instrument' in section $1(1)$ of the Act. In the absence of applicable specific provisions, transactions involving cryptocurrency as a method of payment are subjected to the normal tax principles applicable to barter transactions (Berger 2016:78).

A further distinguishing feature of cryptocurrency is how it could come into circulation. Most issued financial instruments represent a contract between the issuer and the holder (Venter 2016:12). In contrast, almost 70\% of cryptocurrency (based on market capitalisation) comes into circulation through cryptocurrency mining (Redman 2019). Subjecting cryptocurrency to the normal tax treatment applicable to financial instruments without regard to these distinguishing features may contribute to issues in the normal tax treatment of cryptocurrency.

\section{Research purpose and objectives}

The objective of this article was to provide an analysis of certain issues in the normal tax treatment of cryptocurrency transactions. This objective was achieved by answering the following research questions:

- What is the normal tax treatment of cryptocurrency transactions?
- What key issues and practical problems can arise in the normal tax treatment of cryptocurrency?

- How could the key issues and practical problems identified be mitigated?

It is necessary to investigate the research questions listed above from a compliance perspective. An implication of the decentralised nature of cryptocurrency is that there is no centralised intermediary on which the SARS could rely for third-party-reported information regarding taxpayer's income from cryptocurrency transactions. Taxpayer compliance with legislation is generally lower for self-reported income when compared with third-party's reported income (Kleven et al. 2011:651). It stands to reason that issues in the normal tax treatment of cryptocurrency transactions may further decrease taxpayer compliance. Therefore, it is appropriate and necessary to analyse the issues that may arise in the normal tax treatment of cryptocurrency transactions.

\section{Research method and design}

A doctrinal research methodology was adopted. Doctrinal research requires an interpretive and qualitative analysis to determine 'what is the law' (Chynoweth 2008:30). Such an analysis involves critically examining the essential features of legislation and case law to determine the law on the subject matter (Hutchinson \& Duncan 2012:34-35). From this perspective, doctrinal research may be considered to be applied research (Coetsee \& Buys 2018:75). Doctrinal methodology is aligned to the historic research method (Hutchinson \& Duncan 2012:36). However, whereas the historic method requires the examination of primary sources as evidence of fact, the doctrinal method allows for the researcher to interpret primary sources to determine what the law is in circumstances where it is not self-evident (Hutchinson \& Duncan 2012:36).

For this article, the examination of primary and secondary sources was conducted through a desktop literature review. The documentary data examined were predominantly legislation, relevant case law, publications by the SARS and secondary commentary on legislation and case law in the form of journal articles, theses and dissertations. Secondary sources providing commentary on the normal tax treatment of bitcoin (as opposed to cryptocurrency in general) have been cited in this article, where it is appropriate, based on the features of decentralisation and convertibility that are shared by cryptocurrencies as defined by the Financial Action Task Force.

This article falls within the reform-orientated genre of doctrinal research, as it also includes a critical analysis of the existing rules and makes recommendations for change. Therefore, this article is structured as follows. A brief discussion of the normal tax treatment of cryptocurrency transactions, based on the author's interpretation of the identified law and a review of secondary sources, is provided along with an illustrative example. The variety of 
cryptocurrency transactions that may be entered into prevents this discussion from being exhaustive. The key issues identified from a critical analysis of the normal tax treatment of cryptocurrency transactions are then considered through a discursive style, and recommendations, which may address the issues identified, are made. The final section identifies areas for future research, and also provided the conclusion.

\section{The normal tax treatment of cryptocurrency transactions}

The inclusion of cryptocurrency in the definition of 'financial instrument' gave legislative effect to the position of SARS (2018a) that cryptocurrency is an asset, and not a currency, for South African normal tax purposes. Therefore, the exchange of cryptocurrency for goods or services (including the exchange of one cryptocurrency for another) constitutes a barter transaction. The counterparties to a barter transaction establish the relative values of their goods and services and trade them in an equal exchange. It follows, as held in South Atlantic Jazz Festival (Pty) Ltd v CSARS (2015) 77 SATC 254, at 257 , that in an ordinary arm's length barter transaction, the value that the parties attributed to the goods or services exchanged would be a reliable indicator of their equivalent market value.

The SARS had provided guidance regarding the tax treatment of cryptocurrency prior to the enactment of the Taxation Laws Amendment Bill, 2018. In its media release dated 06 April 2018, the SARS indicated that the normal tax treatment of cryptocurrency is governed by 'normal income tax rules' within the existing tax framework. Therefore, it must be determined, based on existing case law, whether a cryptocurrency transaction is to be taxed on revenue or capital account (SARS 2018a). The normal tax treatment of cryptocurrency held on revenue account (as trading stock) and on capital account (as a capital asset) are briefly discussed next, taking into consideration the inclusion of cryptocurrency in the definition of 'financial instrument' in section 1(1) of the Act.

\section{The normal tax treatment of cryptocurrency held as trading stock}

The proceeds from the disposal of cryptocurrency held as trading stock are included in gross income in terms of the general definition of 'gross income' in section 1(1) of the Act (Berger 2016:50). Cryptocurrency is generally disposed of either in exchange for fiat currency or in exchange for goods and services from merchants accepting cryptocurrency as a form of payment (Parsons 2014:9). It was held in WH Lategan $v$ CIR (1926) 2 SATC 16, at 19, that the term 'amount' includes not only money but also the value of every form of property earned by the taxpayer, which has a monetary value, whether corporeal or incorporeal. Where the taxpayer uses cryptocurrency to purchase goods and services (including the exchange of one cryptocurrency for another), the market value of the goods or services received thus constitutes an amount to be included in gross income (Wicht 2016:62).

Taxpayers typically acquire cryptocurrency in one of the following three ways: by purchasing cryptocurrency with fiat currency, for example, on a cryptocurrency exchange; by receiving cryptocurrency in exchange for goods and services as a party to a barter transaction; or (in the case of mined cryptocurrencies such as bitcoin) by generating cryptocurrency through the process of cryptocurrency mining (Wicht 2016:21). The expenditure incurred in the acquisition of trading stock is generally deducted in terms of section 11(a) of the Act, provided that all the requirements of the general deduction formula are met. Therefore, the cost price of cryptocurrency held as trading stock, which was purchased with fiat currency, is deductible for normal tax purposes.

Furthermore, expenditure includes not only money spent but also payments made through the transfer of other assets with a monetary value (De Koker \& Williams 2019:7.4). It was held in ITC 1783 (2004) 66 SATC 373, at 376, that expenditure may also include the spending of time or labour. The decision in Caltex Oil (SA) Ltd $v$ SIR(1975) 37 SATC 1 indicates that the market value of the taxpayer's performance in terms of a barter transaction must be valued in rands in order to be claimed as a deduction. Consequently, the market value of goods or services transferred in exchange for cryptocurrency in a barter transaction may be allowed as a deduction in terms of the general deduction formula. Based on the principles held in the South Atlantic Jazz Festival case, the market value of the goods and services transferred would be equivalent to the market value of the cryptocurrency acquired. The cryptocurrency acquired as counter-performance in terms of the barter transaction may be included in gross income in terms of the general definition of 'gross income' in section 1(1) of the Act (Berger 2016:50) or when it is received for the rendering of services in terms of paragraph (c) (Parsons 2014:9) or paragraph (i) for the definition of 'gross income' in section 1(1) of the Act.

As noted previously, some cryptocurrencies may also be acquired through cryptocurrency mining. Cryptocurrency mining is the process through which new units of cryptocurrency are generated and brought into circulation (Nakamoto 2008:4). Units of cryptocurrency are received by the miner when computationally verifying transactions in a public log known as the blockchain (Ciaian, Rajcaniova \& Kancs 2016:1801). This verification process is performed using cryptocurrency mining software on a computer (Ciaian et al. 2016:1801). Taxpayers usually engage in cryptocurrency mining with the intention of earning an income (Parsons 2014:8). Cryptocurrency acquired through cryptocurrency mining gives rise to an immediate receipt or accrual, and it is subsequently held as trading stock until it is disposed of (SARS 2018a). It has been submitted that the inclusion of this immediate receipt or accrual in gross income may be in terms of paragraph (c) of the definition of 'gross income' in section $1(1)$ of the Act, as the mining process is essentially a transaction 
validation service, which is rendered to the cryptocurrency network (Coelho 2017:9; Parsons 2014:10). The expenditure incurred when mining cryptocurrency, such as electricity costs, may be allowed as deductions if the requirements of the general deduction formula are met, which depend on the facts of the case.

Section 22(1)(a) of the Act will require that the value of cryptocurrency held and not disposed of at the end of the year of assessment (i.e. the value of closing stock) be included in the determination of taxable income (Berger 2016:73). The classification of cryptocurrency as a financial instrument prevents taxpayers from reducing the cost price to be included in taxable income in terms of section 22(1)(a) of the Act by any amount by which the value of cryptocurrency has diminished owing to, inter alia, a decrease in market value. The value to be included in the determination of taxable income is therefore the cost price.

In terms of section 22(3)(a)(i) of the Act, the cost price of trading stock, for section 22 of the Act, is the cost incurred by the taxpayer in acquiring the trading stock, plus any further costs incurred to bring the trading stock into its existing condition and location, excluding any exchange differences. The taxpayer may be charged transaction fees by cryptocurrency exchanges when purchasing cryptocurrency with fiat currency (Coelho 2017:12). It appears (based on the wording of section 22(3)(a)(i) of the Act) that where cryptocurrency is purchased with fiat currency on a cryptocurrency exchange, the cost price for the purposes of section 22(1)(a) of the Act may include the transaction fees charged by the exchange. Where cryptocurrency is acquired in exchange for goods or services in terms of a barter transaction, the cost price may be the market value of the goods or services exchanged.

The cost price of cryptocurrency held at the beginning of the year of assessment (i.e. opening stock) is deductible as the opening stock in the determination of taxable income in terms of section 22(2) of the Act. Therefore, the mechanics of section 22(1)(a) of the Act, in conjunction with section 22(2) of the Act, effectively prevent the taxpayer from reducing taxable income by the expenditure incurred to acquire cryptocurrency until such time as the cryptocurrency is disposed of. The application of the above principles to a natural person transacting with cryptocurrency is illustrated by the following example.

A taxpayer renders services to a customer for one unit of cryptocurrency on 25 September 2018, when the market value of one unit of cryptocurrency is equal to R55 652. The taxpayer incurs deductible expenses of R46 380 in production of this income. The taxpayer has accepted the cryptocurrency as payment with the intention to exchange it for rand in the short term to realise speculative profits. The cryptocurrency may thus be regarded as trading stock from the outset. The taxpayer exchanges the cryptocurrency for R93 853 on 09 April 2019.
The normal tax consequences for the 2019 year of assessment are as follows. The amount of R55 652 (the market value of the cryptocurrency received) may be included in the taxpayer's gross income redundant as it states that these are the normal tax consequences for the 2019 year of assessment in terms of paragraph (c) of the definition of 'gross income' in section 1(1) of the Act. As the cryptocurrency was received in terms of a barter transaction, the taxpayer may claim a deduction in terms of section 11(a) of the Act with respect to the services transferred to acquire the cryptocurrency as trading stock to an equivalent value of R55 652. The taxpayer may also claim deductions of R46 380 in terms of section 11(a) of the Act. The cryptocurrency constitutes trading stock held and not disposed of by the taxpayer at the end of the 2019 year of assessment, and the cost price is consequently included in determining taxable income in terms of section 22(1)(a) of the Act. In terms of section 22(3) of the Act, the cost price to be included is the expenditure incurred to acquire the cryptocurrency in terms of the barter transaction of R55 652. The net effect on the taxpayer's taxable income for the 2019 year of assessment is R9 272 (R55 652 - R55 652 - R46 380 + R55 652). This is aligned to the taxpayer's net economic gain, as it is equal to the difference between the market value of the cryptocurrency received and the deductible expenses incurred in production of income.

In the 2020 year of assessment, the taxpayer may claim a deduction for opening stock of R55 652 in terms of section 22(2)(a) of the Act. The proceeds from the disposal of the cryptocurrency of R93 853 are included in gross income in terms of the general definition of 'gross income' in section 1(1) of the Act. Therefore, the net effect on the taxpayer's taxable income for the 2020 year of assessment is R38 201 (R93 853 - R55 652). This is aligned to the taxpayer's net economic gain, as it represents the profit resulting from an appreciation in the market value of the cryptocurrency.

Similar principles as those applied in the above example would apply in the case of a barter transaction where cryptocurrency is received in exchange for goods, including where one cryptocurrency is exchanged for another.

\section{The normal tax treatment of cryptocurrency held as a capital asset}

Cryptocurrency may constitute a capital asset where, for example, the taxpayer obtains cryptocurrency as a long-term investment (Berger 2016:54). The disposal of cryptocurrency held as a capital asset is subjected to the provisions of the Eighth Schedule to the Act (Eighth Schedule) (SARS 2018a). Consequently, both the sale of cryptocurrency for fiat currency and the use of cryptocurrency to purchase goods and services (including the exchange of one cryptocurrency for another) may constitute the disposal of a capital asset and give rise to a capital gain or loss. The capital gain or loss is determined with reference to the base cost and proceeds of 
the cryptocurrency disposed of. Where cryptocurrency is disposed of in exchange for goods and services, the proceeds will be the market value of those goods and services based on paragraph 35(1) of the Eighth Schedule and the meaning of 'amount' as established by the Lategan case.

The base cost of cryptocurrency depends on the manner of acquisition. Where cryptocurrency was acquired on a cryptocurrency exchange with fiat currency, the base cost will be the amount paid for cryptocurrency plus any fees charged by the exchange, based on paragraph 20(1)(a) of the Eighth Schedule. The base cost of cryptocurrency acquired in exchange for goods would be the market value of the goods exchanged, as the market value of the goods exchanged constitutes expenditure (based on the principles of ITC 1783). The base cost of cryptocurrency acquired in exchange for services would, in terms of paragraph 20(1)(h)(ii)(dd) of the Eighth Schedule, be the amount that has been included in the taxpayer's gross income as consideration for the services rendered (i.e. the market value of cryptocurrency upon initial receipt thereof). Where a taxpayer can prove that cryptocurrency acquired through cryptocurrency mining constitutes a capital asset, the same provision is applied to such cryptocurrency if the initial receipt thereof was included in gross income in terms of paragraph (c) of the definition of 'gross income' in section 1(1) of the Act.

Notwithstanding the above discussion, paragraph 42 of the Eighth Schedule provides that the proceeds from the sale of a financial instrument are deemed to be equal to the base cost thereof, where the financial instrument is disposed of at a capital loss and an identical financial instrument is acquired within 91 days. Paragraph 42 of the Eighth Schedule is essentially an anti-avoidance provision aimed at preventing the artificial realisation of capital losses on financial instruments. Therefore, the capital loss on certain cryptocurrency transactions may not be taken into account at the time of disposal. Instead, the capital loss is added to the base cost of the identical cryptocurrency acquired.

In terms of paragraph 53(3)(e) of the Eighth Schedule, personal-use assets do not include financial instruments. An individual obtaining cryptocurrency to purchase goods and services for personal use may therefore not disregard the gain or loss resulting from these transactions in terms of paragraph 53 of the Eighth Schedule. The Explanatory Memorandum on the Taxation Laws Amendment Bill, 2018, highlights this point (National Treasury 2019:42).

Owing to their digital form, all cryptocurrencies have the potential to be infinitely divisible. For example, one bitcoin is currently, in general, divided up to eight decimal places (with the smaller unit of bitcoin known as 'satoshi') (Brandvold et al. 2015:23). Therefore, a unit of cryptocurrency does not always have to be sold in its entirety. Paragraph 33 of the Eighth Schedule provides that where only a part of an asset is disposed of, the base cost of the part disposed of would be a pro-rata portion of the allowable expenditure of the entire asset based on the market value immediately prior to disposal. The base cost of the remaining part of the asset is reduced by the pro rata portion attributable to the part disposed of. Paragraph 33 of the Eighth Schedule could therefore be taken into account in determining the base cost of cryptocurrency, where a unit of cryptocurrency is not sold in its entirety.

\section{Issues identified in the normal tax treatment of cryptocurrency}

The author has identified certain key issues that taxpayers may encounter in applying the normal tax treatment set out above to cryptocurrency transactions. These issues, and recommendations as to how they may be addressed, are set out below.

\section{Determining whether a taxpayer holds cryptocurrency on revenue or capital account}

The Comprehensive Guide to Capital Gains Tax (Issue 7) suggests that cryptocurrencies with volatile prices are likely to be held as speculative assets of a revenue nature (SARS 2018b:50). Speculative assets of a revenue nature would generally fall within the definition of trading stock. Consequently, the Comprehensive Guide to Capital Gains Tax may indicate a predisposition of the SARS to regard cryptocurrency as trading stock, rather than as a capital asset. That notwithstanding, the SARS media release regarding cryptocurrency indicates that the existing case law should be applied to determine whether a receipt or accrual relating to cryptocurrency is capital or revenue in nature (SARS 2018a).

Unlike many other financial instruments, cryptocurrency generally does not earn dividends or interest, although exceptions do exist (Cunningham 2019). In this regard, the sale of cryptocurrency is considered analogous to the sale of Kruger Rands (Parsons 2014:10). It was held in ITC 1525 (1991) 54 SATC 209, at 210, that the proceeds from the sale of Kruger Rands were revenue in nature, as the Kruger Rands had no income-producing capacity. The court held that the only economic utility of the Kruger Rands was to be turned into cash and that the taxpayer would accordingly have had to envisage selling them when they were originally acquired (ITC 1525, at 210). It may be argued, on the same basis, that cryptocurrency transactions could only be revenue in nature, as cryptocurrency is not an income-producing unit.

However, when considering the judgments in two other cases concerning Kruger Rands, ITC 1355 (1981) 44 SATC 132 and CIR $v$ Nel (1997) 59 SATC 349, cryptocurrency's lack of income-producing capacity may not preclude the proceeds from the sale of cryptocurrency from being capital in nature. The intention of the taxpayer remains paramount in determining whether an amount relating to a cryptocurrency transaction is income or capital in nature (Berger 2016:49; Coelho 2017:9; Parsons 2014:9; Wicht 2016:77). Cryptocurrency held with no intention 
to dispose of at a profit, for example, where it is acquired by a cryptocurrency enthusiast for use as a method of payment, may therefore constitute a capital asset.

Given its use as both a method of payment and a speculative investment, a taxpayer may have more than one intention in relation to cryptocurrency. It was held in Overseas Trust Corporation Ltd v CIR (1926) 2 SATC 71, at 78-79, that where the taxpayer had alternative intentions, one of which being to secure a profit through reselling an asset, the amount received is revenue in nature. A profit-making intention may, however, be assumed (Coelho 2017:9), given the volatility of cryptocurrency prices and its use as a speculative investment (Baek \& Elbeck 2015:33). It was held in African Life Investment Corporation (Pty) Ltd $v$ SIR (1969) 31 SATC 163, at 251, that the proceeds from the sale of shares was revenue in nature as there was more than 'a mere hope or expectation' that the shares would increase in value, given the rising trend of the stock market. Therefore, cryptocurrency gains may be considered revenue in nature, based on the ratio of the African Life Investment Corporation case (Coelho 2017:9). Conversely, in the more recent case of CSARS v Capstone 556 (Pty) Ltd (2016) 78 SATC 231, at 238, Van der Merwe AJA (2016) remarked that:

$[V]$ irtually every capital asset is purchased in the hope and anticipation that it will increase in value and in contemplation of the possibility that it may in future be sold at a profit.

Determining whether a gain resulting from cryptocurrency price fluctuations was merely incidental or a secondary intention of the taxpayer may prove to be challenging.

A correspondence analysis conducted by $\operatorname{Ram}(2018: 214,230)$ also suggested that the characteristics of cryptocurrency may lead to practical difficulty in applying the intention test to cryptocurrency transactions. The analysis revealed that it may be appropriate to determine the normal tax treatment of cryptocurrency with reference to the way it is acquired as opposed to, the intention with which it is acquired (Ram 2018:214). This approach is contrary to the existing South African case law (Ram 2018:214).

The practical difficulties that may arise in determining whether a taxpayer holds cryptocurrency on revenue or capital account may be partially mitigated by considering the period for which cryptocurrency was held. The difficulties of applying the existing case law to determine the revenue or the capital nature of the gains realised on the sale of equity shares was addressed through the introduction of section $9 \mathrm{C}$ of the Act in 2007 (National Treasury 2015:16). Section 9C of the Act deems the gains from the disposal of qualifying shares to be of capital nature if the shares were held for a continuous period of three years. It may be appropriate for the legislature to introduce a similar provision regarding cryptocurrency. At the least, the SARS should provide further guidance regarding the capital or revenue classification of cryptocurrency transactions in the Comprehensive Guide to Capital Gains Tax. Such further guidance is justified considering the uncertainty that may arise because of the distinguishing characteristics of cryptocurrency as discussed.

\section{Permissible deductions where the taxpayer acquires cryptocurrency through cryptocurrency mining}

It has been noted earlier in this article that cryptocurrency acquired through cryptocurrency mining gives rise to an immediate receipt or accrual and is subsequently held as trading stock until it is disposed of (SARS 2018a). It was further noted that the proceeds from the disposal of cryptocurrency held as trading stock may be included in gross income. Therefore, both the initial receipt and the subsequent disposal of cryptocurrency acquired through cryptocurrency mining would meet the requirements of inclusion in gross income.

A taxpayer mining cryptocurrency is essentially providing a transaction validation service to the cryptocurrency network by computationally verifying transactions in the blockchain (Coelho 2017:9; Parsons 2014:10). It is evident from the example presented earlier in this article that where cryptocurrency is received in exchange for services, the application of the general principles of the Act aligns the taxpayer's taxable income to the taxpayer's net economic gain. The example shows that a deduction of the market value of the services provided in exchange of the cryptocurrency received, which is equivalent to the market value of the cryptocurrency received, is crucial for creating this alignment. The aforementioned deduction is distinct from the permissible deductions for costs incurred to enable the rendering of the service.

Providing the transaction validation service to the cryptocurrency network may constitute expenditure, based on the principles established in ITC 1783, as discussed previously in this article. Furthermore, the amount of this expenditure is equal to the value of the transaction validation service provided, based on the principles of the Caltex Oilcase. Section 102(1)(b) of the Tax Administration Act No. 28 of 2011 places the burden of proving that an amount is deductible on the taxpayer. Therefore, in order to claim a deduction for the expenditure incurred to acquire the cryptocurrency (as distinct from a deduction of the costs incurred to enable the mining of the cryptocurrency, for example, electricity costs incurred), the taxpayer must quantify the value of the service provided to the cryptocurrency network.

The author submits, for reasons to follow, that the taxpayer cannot rely on the principles held in the South Atlantic Jazz Festival case to attribute a value to the transaction validation service provided to the cryptocurrency network. In a barter transaction, the counterparties to the transaction engage in an equal exchange based on what they agree the relative values of the goods and services exchanged to be. When a taxpayer successfully uses the taxpayer's computer to add a block to the blockchain by validating transactions, the taxpayer's computer receives the ability to create a fixed 
quantity of new units of the cryptocurrency (Bal 2014:57). The fixed quantity of new units is determined by the blockchain protocol (Bal 2014:57) and does not vary depending on the number of transactions verified or the amount of computing power expended to create the block. It follows that the cryptocurrency network does not perform an arm's length valuation of the services rendered by the taxpayer to determine the amount of cryptocurrency received by the taxpayer. Therefore, the amount of expenditure incurred by the taxpayer to acquire the cryptocurrency cannot be taken as equivalent to the market value of the cryptocurrency received for normal tax purposes. Given the nature of the service provided, there may be practical difficulties for the taxpayer to quantify the expenditure incurred and prove that an amount is deductible. This may lead to a misalignment between the taxpayer's taxable income and the net economic gain.

This problem will not arise if the cryptocurrency was held as a capital asset because of the working of paragraph 20(1)(h)(ii)(dd) of the Eighth Schedule, as discussed earlier in this article. One possible solution to this problem would be to treat cryptocurrency acquired through cryptocurrency mining as trading stock acquired for a consideration, which is not measurable in terms of money. The cost price of trading stock acquired 'for no consideration or for a consideration which is not measurable in terms of money', for the purposes of section 22 of the Act, is deemed to be the market value on the date on which the trading stock was acquired (in terms of section 22(4) of the Act). In practice, the SARS allows the market value on the date of acquisition of trading stock acquired for consideration, which is not measurable in terms of money as part of the deduction of opening stock in terms of section 22(2)(b) of the Act (De Koker \& Williams 2019:8.112). Applying this practice to cryptocurrency acquired through cryptocurrency mining would align the taxpayer's taxable income with the taxpayer's economic gain. However, the taxpayer would rely on the practice of SARS to claim a deduction in terms of section 22(2)(b) of the Act. It was held in Ernst Bester Trust $v$ CSARS (2008) 70 SATC 151, at 154, that there is no statutory authority for this practice. It is recommended that this practice be codified to provide greater certainty to taxpayers.

\section{Allocating the cost price of cryptocurrency}

It was noted earlier in this article that the cost price of cryptocurrency held as trading stock at the end of the year of assessment must be included in taxable income in terms of section 22(1)(a) of the Act. In order to adhere to this provision, a taxpayer is required to allocate the cost of cryptocurrency purchased between those units of cryptocurrency sold during the year of assessment and those units of cryptocurrency on hand at the end of the year of assessment. A taxpayer is also required to determine the base cost of cryptocurrency disposed of for capital gains tax purposes where cryptocurrency is held as a capital asset, necessitating a similar allocation.

Units of cryptocurrency are fungible (Carrick 2016:2323) and may be perfectly substituted for each other. Therefore, it may be difficult for the taxpayer to determine the cost price of cryptocurrency held at the end of the year of assessment (Coelho 2017:10) or to determine the cost of a specific unit of cryptocurrency (Wiseman 2016:419, 434). Financial accounting theory recognises various cost formulas for allocating cost between items sold and items on hand, such as the first-in, first-out method; last-in, last-out method; specific identification method; standard cost method; retail method; and weighted average cost method (De Koker \& Williams 2019:8.111).

Section 22(5) of the Act prohibits the use of the last-in, lastout method in determining the cost price of trading stock. Therefore, it would appear that taxpayers may adopt the other aforementioned methods, where appropriate, for the purpose of section 22 of the Act (De Koker \& Williams 2019:8.111). The SARS usually allows the use of the weighted average cost method to determine the cost price of trading stock on hand (De Koker \& Williams 2019:8.111). Cryptocurrency, held as capital assets, may qualify as identical assets in terms of paragraph 32 of the Eighth Schedule. Paragraph 32 of the Eighth Schedule allows the use of the weighted average cost method in allocating the cost price of financial instruments, but only where the financial instruments are listed on a recognised exchange. Therefore, the weighted average cost method is not currently allowed in allocating the cost price of cryptocurrency held as a capital asset. Consequently, the base cost of cryptocurrency could be determined using either the firstin, first-out method or the specific identification method. These methods may prove challenging for taxpayers to apply, compared to the relative simplicity of the weighted average cost method, as they cannot rely on a regulated third-party intermediary to maintain accurate and complete information regarding their cryptocurrency transactions.

With regard to the base cost of identical assets, the Comprehensive Guide to Capital Gains Tax indicates that shares that have been dematerialised and are not identifiable through share certificate numbers are identified by the date of acquisition for the purpose of applying the specific identification method (SARS 2018b:327). The Tax Guide for Share Owners specifies that the taxpayer must maintain detailed records of the dates and costs at which shares were acquired in order to apply this method (SARS 2017:23). It appears reasonable that this approach could be allowed for determining the cost price of cryptocurrency. As the prices of cryptocurrencies are highly volatile (Venter 2016:11), the methods available to allocate the cost price of cryptocurrency may have a significant impact on the taxpayer's taxable income. Therefore, it is recommended that the SARS must provide guidance on record-keeping requirements to taxpayers conducting cryptocurrency transactions. 


\section{Conclusion}

The amendment to the definition of 'financial instrument' in section 1(1) of the Act to include cryptocurrency has fulfilled, to some extent, its purpose of clarifying the normal tax treatment of cryptocurrency. It has clarified that cryptocurrency is an asset, and not a currency, for South African normal tax purposes. Therefore, the exchange of cryptocurrency for goods and services constitutes a barter transaction subjected to the general principles of the Act. Furthermore, the normal tax treatment of cryptocurrency transactions depends on whether the taxpayer holds cryptocurrency on revenue account (as trading stock) or on capital account (as capital asset). Determining whether a taxpayer holds cryptocurrency on revenue or capital account may give rise to practical difficulties. The SARS should provide further guidance on this matter so that taxpayers do not transact in a state of uncertainty.

The proceeds from the disposal of cryptocurrency held as trading stock are included in gross income. Expenses incurred to acquire cryptocurrency held as trading stock are deducted from income if the requirements of the general deduction formula are met. In conjunction with the application of section 22 of the Act to the opening and the closing stock of cryptocurrency, this effectively results in the taxpayer including the gain or loss on the disposal of cryptocurrency held as trading stock in taxable income in the year of assessment in which it is disposed of.

The initial receipt of cryptocurrency acquired through cryptocurrency mining may give rise to an immediate inclusion in gross income. When a taxpayer subsequently disposes of such cryptocurrency held as trading stock, the proceeds from the disposal are also included in gross income. If the taxpayer is not permitted a deduction equal to the market value of the cryptocurrency when it was acquired, as distinct from the deductions allowable for the costs incurred to enable the mining of the cryptocurrency, the taxpayer's taxable income is misaligned with the taxpayer's economic gain. This problem could be addressed by the SARS by firstly allowing the application of section 22(4) of the Act to cryptocurrency acquired through cryptocurrency mining, and secondly allowing a deduction in terms of section 22(2)(b) of the Act with respect to the acquisition of such cryptocurrency.

The disposal of cryptocurrency held as a capital asset may give rise to a capital gain or loss. The inclusion of cryptocurrency in the definition of 'financial instrument' in section 1(1) of the Act prevents the taxpayer from disregarding gains or losses on the basis that cryptocurrency constitutes a personal-use asset. A further result is that certain capital losses on the disposal of cryptocurrency are subjected to the anti-avoidance provision provided in paragraph 42 of the Eighth Schedule.

Determining the base cost of cryptocurrency disposed of may necessitate a cost allocation between identical units of cryptocurrency disposed of and units of cryptocurrency that are still on hand. As cryptocurrencies constitute identical assets, but are not listed on a recognised exchange, the base cost of cryptocurrency may be determined using either the first-in, first-out method or the specific identification method. A cost allocation is also required in applying the provisions of section 22 of the Act to cryptocurrency held as trading stock. It is recommended that the SARS must provide guidance on record-keeping requirements for taxpayers conducting cryptocurrency transactions, as this may impact the cost-allocation methods available to taxpayers for normal tax purposes.

This article has discussed certain key issues in the normal tax treatment of cryptocurrency as identified by the author. The discussion is by no means exhaustive, in part because of the variety of characteristics that cryptocurrencies may have and the variety of cryptocurrency transactions that may be entered into. The discussion in this article has been limited to cryptocurrencies that are intended to function as a medium of exchange. Further research could be performed on the normal tax treatment of other crypto-assets and non-mined cryptocurrencies, the tax consequences of initial coin offerings and the normal tax treatment of cryptocurrency loans and derivatives. Research into the enforceability of the taxation of cryptocurrency transactions should also be conducted to prevent losses to the fiscus. Furthermore, the tax authorities of various other tax jurisdictions have provided extensive guidance on the normal tax treatment of cryptocurrency transactions subsequent to the comparative analyses performed by Berger (2016) and Wicht (2016). The author is of the view that an updated comparative analysis is warranted.

\section{Acknowledgements}

The research conducted for this article emanates from the author's master's degree in taxation (Stellenbosch University), completed under the supervision of Ellané van Wyk.

\section{Competing interests}

The author has declared that no competing interests exist.

\section{Author's contributions}

I declare that I am the sole author of this research article.

\section{Ethical considerations}

Ethical clearance to conduct the study was obtained from the Research Ethics Committee (REC): Humanities, Stellenbosch University (Ethical Clearance No.: ACC-2017-1910) on 13 November 2017.

\section{Funding information}

This research received no specific grant from any funding agency in the public, commercial or not-for-profit sectors. 


\section{Data availability statement}

Data sharing is not applicable to this article as no new data were created or analysed in this study.

\section{Disclaimer}

The views and opinions expressed in this article are those of the author and do not necessarily reflect the official policy or position of any affiliated agency of the author.

\section{References}

African Life Investment Corporation (Pty) Ltd v SIR (1969) 31 SATC 163.

Baek, C. \& Elbeck, M., 2015, 'Bitcoins as an investment or speculative vehicle? A first look', Applied Economics Letters 22(1), 30-34. https://doi.org/10.1080/13504851. 2014.916379

Bal, A.M., 2014, 'Taxation of virtual currency', Doctoral dissertation, Universiteit Leiden, Leiden, the Netherlands.

Baur, D.G., Hong, K.H. \& Lee, A.D., 2018, 'Bitcoin: Medium of exchange or speculative assets?', Journal of International Financial Markets, Institutions and Money May 2018(54), 177-189. https://doi.org/10.1016/j.intfin.2017.12.004

Berger, L.L., 2016, 'Bitcoin exchange transactions : Income tax implications to consider within the South African environment', Master's thesis, School of Accounting Sciences, North-West University, Potchefstroom.

Brandvold, M., Molnár, P., Vagstad, K. \& Andreas Valstad, O.C., 2015, 'Price discovery on bitcoin exchanges', Journal of International Financial Markets, Institutions and Money May 2015(36), 18-35. https://doi.org/10.1016/j.intfin.2015.02.010

Caltex Oil (SA) Ltd v SIR(1975) 37 SATC 1.

Carrick, J.,2016,'Bitcoin as a complement to emerging market currencies', Emerging Markets Finance and Trade 52(10), 2321-2334. https://doi.org/10.1080/154049 6X.2016.1193002

Chynoweth, P., 2008, 'Legal research', in A. Knight \& L. Ruddock (eds.), Advanced research methods in the built environment, pp. 28-37, Wiley-Blackwell, West Sussex.

Ciaian, P., Rajcaniova, M. \& Kancs, D., 2016, 'The economics of bitcoin price formation', Applied Economics 48(19), 1799-1815. https://doi.org/10.1080/00036846.2015. 1109038

CIR v Nel (1997) 59 SATC 349

Coelho, A.S., 2017, 'The tax and exchange control consequences of virtual currency transactions in South Africa', Master's thesis, Department of Commercial Law, University of Cape Town, Cape Town.

Coetsee, D. \& Buys, P., 2018, 'A doctrinal research perspective of master's degree students in accounting', South African Journal of Higher Education 32(1), 71-89. https://doi.org/10.20853/32-1-1516

CSARS v Capstone 556 (Pty) Ltd (2016) 78 SATC 231.

Cunningham, S., 2019, 'How to earn interest on holding your crypto', in Cryptocurrency hub, viewed 16 June 2019, from https://cryptocurrencyhub.io/how-to-earninterest-on-holding-your-crypto-b684893e9d2a.

De Jager, P., Parsons, S. \& Roeleveld, J.J., 2012, 'A commentary on SARS' proposed fair value tax on financial instruments', South African Journal of Accounting Research 26(1), 165-184. https://doi.org/10.1080/10291954.2012.11435168

De Koker, A.P. \& Williams, R.C., 2019, Silke on South African income tax, viewed 16 June 2019, from https://www.mylexisnexis.co.za.

Ernst Bester Trust v CSARS (2008) 70 SATC 151.
Financial Action Task Force, 2014, Virtual currencies: Key definitions and potential AML/CFT risks, viewed 15 June 2016, from https://www.fatf-gafi.org/media/ fatf/documents/reports/Virtual-currency-key-definitions-and-potential-aml-cftrisks.pdf.

Hutchinson, T. \& Duncan, N., 2012, 'Defining and describing what we do: Doctrinal legal research', Deakin Law Review 17(1), 83-119. https://doi.org/10.21153/ dlr2012vol17no1art70

ITC 1355 (1981) 44 SATC 132.

ITC 1525 (1991) 54 SATC 209.

ITC 1783 (2004) 66 SATC 373.

Kleven, H.J., Knudsen, M.B., Kreiner, C.T., Pedersen, S. \& Saez, E., 2011, 'Unwilling or unable to cheat? Evidence from a tax audit experiment in Denmark', Econometrica 79(3), 651-692. https://doi.org/10.3982/ECTA9113

Maroun, W., 2015, 'Peculiarities of the fair value taxation regime for financial instruments', South African Journal of Accounting Research 29(2), 151-161. https://doi.org/10.1080/10291954.2015.1006484

Nakamoto, S., 2008, Bitcoin: A peer-to-peer electronic cash system, viewed 20 June 2016, from https://bitcoin.org/bitcoin.pdf.

National Treasury, 2015, Explanatory memorandum on the taxation laws amendment bill, 2015, National Treasury, Government of South Africa, Pretoria.

National Treasury, 2019, Explanatory memorandum on the taxation laws amendment bill, 2018, National Treasury, Government of South Africa, Pretoria.

Organisation for Economic Cooperation and Development (OECD), 1998, Electronic commerce taxation framework conditions, viewed 20 June 2016, from https:// www.oecd.org/tax/consumptiontax/1923256.pdf\%5Cnhttp://www.biac.org/ members/tax/BEPS/Ottawa_tax_Framework_923256.pdf.

Overseas Trust Corporation Ltd v CIR(1926) 2 SATC 71.

Parsons, S., 2014, 'What is bitcoin? The potential tax consequences of transacting in virtual currency in South Africa', Proceedings of the 2014 SAAA regional conference, Cape Town, 08 August, 2014, pp. 3-13.

Ram, A.J., 2018, 'Taxation of the bitcoin: Initial insights through a correspondence analysis', Meditari Accountancy Research 26(2), 214-240. https://doi.org/10. 1108/MEDAR-10-2017-0229.

Redman, J, 2019, 'Mineable cryptocurrencies are far more valuable than non-mineable coins', Bitcoin.com News, viewed 16 June 2019, from https://news. bitcoin.com/mineable-cryptocurrencies-are-far-more-valuable-than-nonmineable-coins/.

South African Government, 1962, Income Tax Act, No. 58 of 1962, Government Printer, South African Government, Pretoria.

South African Revenue Service (SARS), 2017, Tax guide for share owners (issue 6), Legal Counsel, SARS, Pretoria.

South African Revenue Service (SARS), 2018a, SARS's stance on the tax treatment of cryptocurrencies, media release 06 April 2018, SARS, Pretoria, viewed 10 April cryptocurrencies, media release 06 April 2018, SARS, Pretoria, viewed 10 April 2018, from https://www.sars.gov.za/Media/MediaReleases/Page
-SARS-stance-on-the-tax-treatment-of-cryptocurrencies-.aspx.

South African Revenue Service (SARS), 2018b, Comprehensive guide to capital gains tax (issue 7), Legal Counsel, SARS, Pretoria.

South Atlantic Jazz Festival (Pty) Ltd v CSARS (2015) 77 SATC 254

Venter, H., 2016, Digital currency: A case for standard setting activity. A perspective by the Australian Accounting Standards Board, viewed 12 March 2018, from https:// www.aasb.gov.au/admin/file/content102/c3/AASB_ASAF_DigitalCurrency.pdf.

WH Lategan v CIR (1926) 2 SATC 16.

Wicht, M.S., 2016, 'The tax implications of bitcoin in South Africa', Master's thesis, Faculty of Law, University of Pretoria, Pretoria.

Wiseman, S.A., 2016, 'Property or currency? The tax dilemma behind bitcoin', Utah Law Review 2016(2), 417-440. 